\title{
COMPARATIVE STUDY OF HEMATOLOGIC AND PLASMA BIOCHEMICAL VARIABLES IN EASTERN ATLANTIC JUVENILE AND ADULT NESTING LOGGERHEAD SEA TURTLES (CARETTA CARETTA)
}

\author{
Casal, A.B. ${ }^{a}$, Camacho, M. ${ }^{a}$, López-Jurado, L.F. ${ }^{\mathrm{b}}$, Juste, C. $^{\mathrm{c}}$, Orós, J. $^{\mathrm{a}}$
}

\footnotetext{
a Departments of Morphology and University of Las Palmas de Gran Canaria, Arucas (Las Palmas), Spain b Dept. of Biology in the Veterinary Faculty and Univ. of Las Palmas de Gran Canaria, Arucas (Las Palmas), Spain c Department of Animal Pathology, University of Las Palmas de Gran Canaria, Arucas (Las Palmas), Spain
}

\begin{abstract}
Background: Plasma biochemical and hematologic variables are important in the management of endangered sea turtles, such as loggerheads. However, studies on blood biochemistry and hematology of loggerheads are limited, and different concentrations according to variable criteria have been reported. Objective: The purpose of this study was to establish and compare baseline plasma chemistry and hematology values in Eastern Atlantic juvenile and adult nesting loggerhead sea turtles (Caretta caretta). Methods: Blood samples were collected from 69 healthy juvenile loggerhead sea turtles after their rehabilitation in captivity, and from 34 adult nesting loggerheads after oviposition. Fresh blood was used for leukocyte differential count and PCV determination. Heparinized blood was used for RBC and WBC counts. Plasma biochemical concentrations were measured using an automated biochemical analyzer. For the comparative study, nonparametric statistical analysis was done using the Mann-Whitney U-test. Results: Minimum, maximum, and median concentrations were obtained for 14 hematologic and 15 plasma chemistry variables. Statistically significant differences between juvenile and adult turtles were found for PCV; RBC, WBC, and leukocyte differential counts; total protein, albumin, globulins, calcium, triglycerides, glucose, total cholesterol and urea concentrations; and lactate dehydrogenase activity. Conclusions: Age, size, and reproductive status cause important variations in the hematologic and plasma biochemical results of loggerheads. The reference values obtained in this study may be used as a standard profile, useful for veterinary surgeons involved in sea turtle conservation.
\end{abstract}

